\title{
English Language Teaching
}

Vol. 2, No. 2

www.ccsenet.org/journal.html

June 2009

\section{A Sentence Is Not a Complete Thought: X-Word Grammar}

\author{
David E. E. Sloane \\ University of New Haven \\ 300 Boston Post Road \\ West Haven, CT 06516 USA \\ E-mail: dsloane@newhaven.edu
}

\begin{abstract}
$\mathrm{X}$-Word Grammar provides an editing technique for students that is more reliable than trying to identify sentences as complete thoughts. A sentence is redefined as "a group of words that can be turned into a yes-no question with no words left over; starts with a capital letter, and ends with a terminal punctuation mark." Twenty auxiliary verbs play a key role by moving around the subject of a sentence to identify the correct structure of a sentence using both visual and oral means. Stressing editing skills, teachers can use X-Word Grammar as a means to simplify sentence punctuation, address verb endings, carry out other tasks in editing and evaluating writing.
\end{abstract}

Keywords: X-Word Grammar, Editing sentences, Grammar instruction, Punctuation, Writing, Assessment

\section{Introduction}

A sentence is not a complete thought. For years the standard way of describing sentences was in those terms. Grammar books have grown a little more cagey, but the fact remains that we need a better way to train students to identify a sentence and be able to explain it back to us in concrete terms. The terms need to be based in the sentence itself and not in some abstract realm called "thought." As I point out to my "Applied Linguistics" graduate students, I know people who write eloquent sentences and haven't entertained a complete thought in years. Teaching the declarative sentence needs to be practical and functional. With talk of "thoughts," students are mystified. Deprived of a working tool that they can manipulate with confidence, they come to see grammar as an arcane subject best left to English teachers.

\section{Thought versus Structure}

\subsection{The Definition of Sentence as Thought}

What is a complete thought? A complete thought does not have to be a complete sentence; for example, when a disgruntled baseball fan yells out from the bleachers, "Ya, bum, Ya!" I would call that a complete thought. If I utter the phrase, "Fiddling while Rome burns," everybody in the planning session knows what I'm talking about, and in some fairly exact degree of specificity. How can the sentence "It is true." be a complete thought when I don't know what the "It" is? By definition a pronoun stands in place of a noun, and I have no clue as to what that noun is. Based on that argument, I want to avoid abstract answers that deal with ideas. What is meant by a "complete thought" ends up being, by guesswork, the subject and predicate of a sentence, but that doesn't give a complete description either. I need to give prospective teachers a defining method that is based on structure and moves actual words and symbols around mechanically. I want the students to be able to do the same thing quickly. The less thinking, the better; the more mechanics, the more I can see the system replicated by users without having to negotiate thinking or creativity. Thinking and creativity are important, but they need to be put in the most helpful relationship with Edited English that we can employ. I use X-Word Grammar--the subject of this article, because its application from structural linguistics, specifically Tagmemics, gives me a very simple way to use it. The term Edited English is used specifically because the system is best used in relation to editing. X-Word Sentence Grammar gives me a structural tool that I have been using since I first encountered it in Columbia Teachers College courses taught by its creator, Robert L. Allen, in 1975. Does it help? I wish I had a nickel for every student that looked at me after a class in it and said, "Why didn't anybody tell me this before?" I would work no more.

\section{$2.2 \mathrm{X}$-Word Grammar}

$\mathrm{X}$-Word Grammar is based around twenty X-Words, better known as auxiliary verbs. In families, they are [am, is, are,

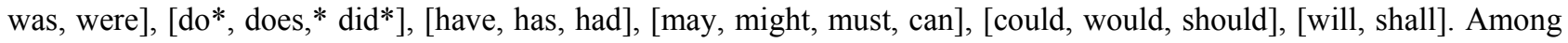
their characteristics are that they go to the front of a normal declarative sentence to make yes-no questions, they combine with verbs to tell time, and they carry negatives (n't), and they are tied to various verbs to make verb phrases. They also identify conditions in other ways, but the functions already named are the ones that are most important to us. 
Especially important is the use of X-Words to make yes-no questions. We can use that structural characteristic to identify what a sentence really is, and we can teach "the sentence" without mystifying abstraction. Before I go further, however, I want to give one caveat. X-Word Grammar was never intended to be a sentence generator to teach creative writing. X-Word Grammar is an analytic system that students can apply to test sentences already written. Student use is more guided by spoken English and oral English training to supply the initial text. That way, students and teachers can use the advantages of learning to write freely without any system but their ideas. Only after an initial creation, often called zero drafting, does the X-Word Grammar system come into play. It serves as an editing benchmark. A mechanical system replaces the reading over and over of ideas that seemed valid to the student whether or not the structure satisfied Edited English expectations. It also serves as a tool to critique sentences and predict reader response the way I teach it.

\section{X-Word Grammar as an Editing System}

\subsection{The Definition of a Sentence}

A sentence in Allen's X-Word Grammar system is defined by three parameters. (1) It begins with a capital letter. (2) It ends with a terminal punctuation mark. (3) In between the capital letter and the terminal punctuation mark it must have a group of words that can be turned into a yes-no question with no words left over. One of the great class-room advantages of this definition is that a little drilling on capital letters and terminal punctuation marks can be used to take much of the anxiety out of the learning process. The students drill on those identifications, master them in minutes, if not seconds, and have completed $66 \%$ of the instruction on what a sentence is. The other $34 \%$ is not much more difficult. Even graduate students love being told they have completed two-thirds of the work in the first minute.

According to this system, sentences are lineal. They are not trees, either ascending or descending, nor are they constructions with slant-lines and platforms. Instead, they are a series of positions which are filled by various words and constructions. Working from this "slot-and-filler," "position-construction" perspective, we can test the sentence itself, with the capitol letter and punctuation.

In the following analysis, my line 1 is the whole sentence. My line 2 is just the words with the markers left out. Lower lines are places where I analyze phrases and various constructions until I have accounted for every word in the sentence. The underlayer of the sentence is the yes-no question with no words left over.

To make the example visual is not hard.

1. My students will write wonderful sentences.

2. my students will write wonderful sentences

Did the sentence begin with a capital letter? Yes, the letter was the capital letter "M." Okay, let's take that away.

Did the sentence end with terminal punctuation? Yes, it used a period (.).

Now my students have got $66 \%$ of the sentence identifiers in place. Even my graduate students laugh at the simplicity of this system, by the way. It always starts with fail-proof components--a natural confidence booster.

The underlayer is the part that has to turn into a yes-no question with no words left over.

3. my students will write wonderful sentences

4. will my students write wonderful sentences

5. X

[S]

$\mathrm{X}<-------[\mathrm{P}]$

will [my students]

write wonderful sentences

[my students] will write wonderful sentences

We can box the subject with X's every time. There are no words left over, and the sentence sounds right. Those are two natural tests for students who have some verbal drilling in saying sentences. From that level we can go further by breaking down each larger chunk into individual words, eventually accounting for everything. After having done this on model sentences with my students, often chanting in unison, the students can then take some of their own sentences and test to see if they are sentences. Some say that they have to change the sentence to make it work. This is a valuable editorial recognition, and they should then keep the revised sentence and replace the previous version with it.

\subsection{Systematic Identification of Subjects as Editing}

A second and important value, to being able to identify the subject mechanically "without thinking," can also come into play. Instead of being in a position where I have to tell a learner that s/he is wrong, I can say, "No, stop thinking!" Telling students they are smart as a way of correcting them turns out to be a very popular teaching device. I will then teach them to do the task mechanically, without "thinking." The subject of a sentence is often said to be what the sentence is about. Such is not the case. In the sentence "It is true that rain is falling." The sentence is about rain. The 
subject box, however, is filled with "It." "It" is the subject of the sentence as far as structure will lead us to the subject. Then what is "rain"!? "Rain" is what almost all of my students pick out when asked to circle the subject. "Rain" can now clearly be labeled as the TOPIC. By separating the idea from the structure, I now have a way to teach my students to consider how their sentence might work on a reader. Do they want to put the topic and subject together? Rain is falling. Do they want to "postpone" the topic, split it off into the predicate, and hold the reader back? X-word grammar students have a way of chunking a sentence meaningfully, assessing its possible effect on a reader, and making their own decision. At the most basic level, they are learning about style. The subject slot/position never moves. It is always between the X's. The topic, on the other hand, can go anywhere, and the student has varied choices concerning what filler/construction goes between the X's.

\subsection{Editing rather than Writing as the Point of Application}

An important caution that is central in using this system is that it is an EDITING system. If the student starts the initial writing from the grammar structure, sentences and overall sentence patterns will become wretchedly stiff and wooden. as we formulate thoughts, we do not normally constrain them that way. First of all, the existence of a manageable editing system allows the students to free-write or zero draft, running with ideas. Structure and grammar should be taught after that, as the next process, after the zero draft is committed to paper so that there is something to edit. Most readers probably see how this makes writing a little less terrifying. When starting out, the system is fail-proof. Grammar and structure can be delayed. I heavily emphasize this point and find that participants up to the level of corporate managers are grateful to be set free. In fact, they are so freed that they may not blurt out at the next cocktail party, "You're an English teacher. Oh, boy, I better watch my grammar."

\subsection{Simplifying Punctuation}

A third benefit of X-Word Grammar as a model for analyzing sentences is that punctuation is now made simpler. Semi-colons are easy. A semi-colon goes between two yes-no questions to tell a reader they are related, but it doesn't tell the reader how. "Comma-and" is the same as a semi-colon, except it tells the reader that the second sentence is added on to the first. "Comma-but," "comma-so," and "comma-for" are described similarly. We can even make a grid. By extension we can also teach "Semicolon-however-comma," "semicolon-nevertheless-comma" and other sentence joiners.

$$
\begin{gathered}
\text { SXP [; ] SXP } \\
\text { SXP [, and] SXP } \\
\text { SXP [, but] SXP } \\
\text { SXP [; however,] SXP } \\
\text { SXP [; nevertheless,] SXP }
\end{gathered}
$$

and as many more as I wish. This is a teaching device I add on to Allen's original system, and it works.

Taught this way, the constructions identified above are all the same, and being uniform, only one rule has to be remembered. This deployment often brings the "why didn't anybody tell me this before?" moment from my adult learners. I have done all this without mentioning "clauses" and "phrases." This system is plain English, unlaced with technical terms.

\subsection{Other Advantages: Identifying Fragments, Explaining the Verb System}

Teaching other aspects of punctuation and sentence structure is built around the basic definition, as well. One obvious question is, "What if a word is left over? An example would be "If all my students will write wonderful sentences." Can we say "Will if..." "If will..."? It looks and sounds strange, and is especially obvious when spoken aloud, which is the best way to introduce would-be editors to this form of analysis. Drilling a behavior is much more effective with many kinds of terrified grammar students than is the expectation that they will find their way through the cognitive forest of clause and phrase terminology, compound, complex, and confusing as it is.

A word left over is another opportunity to begin teaching writers style and what it means to be a true creative writer who can make editorial changes. Take another phrase "Because the semi-colon struck fear into their hearts." An oral test of this phrase by students yields "Did* the semi-colon strike fear into their hearts?" "Yes, the semi-colon did* strike [or struck] fear into their hearts. Some students choose another X-Word, which is also a successful transition. Now, we have to capture what the responders actually said, as opposed to what was written. They instinctively eliminate the extra word "because," again, without thinking. Saying "Because did" or "did because" does not work, and the students can hear it. A number of other forms also show up, like gerund phrases, which can be taught as "one-and-one-half sentences": two predicates sharing the same subject. The half sentence in front has to be walled off with a comma so that we can see where the subject starts. 
Three invisible X-Words offer another important teaching point. Some sentences have no visible X-Word. An example is, "My student writes wonderful sentences." I now have the opportunity to introduce students to the analysis of verb endings. Three X-Words disappear, but they are there, all the same, hiding behind the verb. [DO*-DOES*-DID*] are the three disappearing X-Words. When they appear the tail comes off the verb and goes on the [DO*-DOES*-DID*]; when they disappear we can bring them out again by making the sentence into a yes-no question. Out they pop:

My student writes wonderful sentences. [DOES* + verb]

$\mathrm{X}$

$\mathrm{X}$

Does my student write wonderful sentences? [write has no s now]

My student does write wonderful sentences.

The s-ending and the simple past tense are very much simplified as mechanical requirements. What if DO* has no ending to show? The question form will bring it out. The common declarative sentence responds very well to this sort of analysis. Verbs represent a larger system that is also helped by employing the 20 auxiliary verbs as the center of the editing system. ESL learners get a much simpler explanation of the s- and -ed endings. As for the invisible tail on the $\mathrm{DO}$, at least we have a concept that encompasses it and a way to find it using oral means or visual means, depending on how far the capabilities of our student-editors have progressed.

Longer sentences, of course, require more complex chunking breakdowns, but still adhere to the same system. Gerund phrases fit easily into this system. Longer and more complex registers of time in verbs also need more explanation, but one thing is certain. Time in a sentence is recorded in X-Words and verb endings, so any system that emphasizes the use of X-Words has already placed this area at the heart of the mechanics of the sentence.

\section{Closing Considerations}

\subsection{Effects on Style}

X-Word Grammar was widely used in the New York City school and college systems during the early 1970s with positive results. In fact, the Hunter College-CUNY O.W.L is based on X-Word Grammar. Unfortunately, the system seemed radical, abandoning conventional teaching. I started using the system and working on it while job hunting. One college, although wanting to hire me, did not extend an offer because they were afraid to commit to the new system. So be it. One skeptic wrote an article in which he claimed the system made student writing stilted. He claimed to have found "objectively" that X-Word Grammar students wrote less creatively than non-X-Word Grammar students by pairing two classes, one using X-Word Grammar. The skeptic "experimenter" turned out to have been teaching the system as a writing system to shape the very first words on paper. Of course the X-Word Grammar writers did what he asked. He was teaching them to write subjects and verbs over and over to form their essays. Needless to say, he got what he was teaching. He was not teaching the regular grammar that way. Unhappily, one of the more distinguished journals at the time published this subjective pseudo-scientific comparison. Since the journal declined to print any of a number of very lucid responses, his misapplication stood. It was a grave disservice to the language-teaching community.

\subsection{Assessment: Counting Sentence Structures to Measure Student Progress}

A better way to judge the system would have been to count structures, which I did in a case where a holistic reader had dropped a remedial college freshman from a rating of $2 / 9$ to $1 / 9$, the lowest available, in the course of a semester. Counting structures and sentences revealed that the student had written twice as many words-over four hundred as opposed to just over 200, and had increased the number of sentence attempts from 12 to 17 . The number of errors had remained the same between the two tests, however, and those errors tended to cluster at the front of the essay. The student's writing had advanced considerably- not "improved," but advanced; without a comparison to see what had actually happened, there was no way to objectify the changes. X-Word Grammar structures, however, provided an easy way to count. The problem lay elsewhere. When the student used more sentences, it became more apparent that s/he had little to say, but that was not the fault of the grammar. That problem was caused by a lack of training in ideas and vocabulary. Objectifying our assessment using X-Word Grammar tools would have enabled us to develop a plan to build advance on advance until a much higher level of edited writing was accomplished. The student was identified not as someone who had progressed, but rather as a failure. I think, as teachers, we owed that student a fairer form of assessment.

\section{Summary}

X-Word Grammar offers us potential because of its tight focus on operative language through the twenty auxiliary verbs. Almost any aspect of sentence formation can be approached from this direction. As an editing tool, it allows student editors to distance themselves from the text without "putting it in a drawer for two weeks." Instead, they can look in the subject box to see if a concrete word appears. They can evaluate punctuation as a means to an end in telling a reading about relationships through linking words. Finally, it also has potential as an alternate way of measuring writing change. 
Texts using X-Word Grammar as a teaching system included Robert L. Allen's Working Sentences -a remedial English text--and Alice Deakins' The Tapestry Grammar-a very useful and complete ESL teaching system. Both are now long out of print, but, when my own "Applied Linguistics" students have not snapped them up, copies of Deakins show up in Amazon or A-Libris for no more than two to five dollars. Bonny Hart maintains an X-Word Grammar site at CCNY which contains Jim Lyndon's X-Word Grammar Exercises for Students of English as a Second Language featuring 27 chapters which can be downloaded as PDF $<$ ccnyliteracy.PBwiki.com/Xword+Grammar+Intro+and+Book $+($ pdf $)>$. X-Word Grammar should be returned to our toolbox for teaching students how to manage sentences. The objectivity X-Word Grammar will bring to the editing process will help us teach our students how to edit writing, and it could help us be able to concretely describe how they do it. Both are worthy benefits.

\section{References}

Allen, Doris \& Robert L. and Pompian, Rita. (1975). Working Sentences. New York: Harper \& Row.

Deakins, Alice \& Parry, Kate and Viscount, Robert R. (1994). The Tapestry Grammar/ A Reference for Learners of English. Boston, MA: Heinle \& Heinle.

Lyndon, Jim. (1993). X-Word Grammar Exercises for Students of English as a Second Language <ccnyliteracy.PBwiki.com/Xword+Grammar+Intro+and+Book+(pdf)>. 